\title{
A simple, physically motivated model of sea-level contributions from the Greenland Ice Sheet in response to temperature changes
}

\author{
Alexander M.R. Bakker ${ }^{\mathrm{a}, *}$, Patrick J. Applegate ${ }^{\mathrm{a}}$, Klaus Keller ${ }^{\mathrm{a}, \mathrm{b}, \mathrm{c}}$ \\ ${ }^{a}$ Earth and Environmental Sciences Institute, Pennsylvania State University, University \\ Park, PA 16802, USA \\ ${ }^{b}$ Department of Geosciences, Pennsylvania State University, University Park, PA 16802, \\ USA \\ ${ }^{c}$ Department of Enginering and Public Policy, Carnegie Mellon University, Pittsburgh, \\ PA 15289, USA
}

\begin{abstract}
Sea level could rise by several meters over the next centuries. The Greenland Ice Sheet could be an important contributor to future sea-level rise, because of its large volume and its high sensitivity to surface air temperature increases. Frameworks for the integrated climate risk management often require fast, simplified treatments of sea-level rise, in particular for estimating the risks associated with low probabilities but potentially high impacts. State-of-the-art ice sheet models provide important insights, but are often computationally too demanding to evaluate tail-area risks. Here we present SIMPLE, a physically motivated model of the Greenland ice sheet in response to temperature changes. SIMPLE can skillfully reproduce the results from a three-dimensional ice sheet model and outperforms existing simple models, after similar calibration. We anticipate that SIMPLE will be calibrated to
\end{abstract}

${ }^{*}$ Corresponding author

Preprint submitted to Environmental Modelling \&3 Software

April 18, 2016

(C) 2016. This manuscript version is made available under the Elsevier user license http://www.elsevier.com/open-access/userlicense/1.0/ 
other ice sheet models and can provide a fast approximation (emulator) for such models in studies that require many model evaluations.

Keywords: Greenland ice sheet, semi-empirical model, sea level change, emulator, scenario, geo-engineering

\section{Introduction}

The response of the Greenland Ice Sheet (GIS) to anthropogenic climate change is an important, but deeply uncertain factor determining future sealevel change (Meehl et al., 2007; Church et al., 2013; Moore et al., 2013, 2010; Applegate and Keller, 2015). Total melting of the GIS would lead to an increase in global mean sea level of approximately 7.4 meters (Bamber et al., 2013). The time needed for complete melting of the GIS is, however, deeply uncertain. The lowest published estimate of the time required for total loss of the GIS is $300 \mathrm{yr}$ (Lenton et al., 2008), but most likely this time scale strongly depends on the magnitude of the temperature forcing (Applegate et al., 2015b; Robinson et al., 2012). Some have argued that geo-engineering can help the ice sheets to regrow (Moore et al., 2010; Irvine et al., 2012). Yet, regrowth of the GIS may be considerably slower than the melting (Applegate et al., 2015b; Applegate and Keller, 2015). Anticipating future sea-level rise requires a careful consideration of the relevant sources of uncertainty (e.g. Lempert et al., 2012).

Many applications require fast treatments of sea-level rise, including Integrated Assessment Models (IAMs; e.g. Nordhaus, 2008) and decision support frameworks such as (Many Objective) Robust Decision Making (RDM, MORDM; Lempert et al., 2003; Hall et al., 2012; Hadka et al., 2015). IAMs 
represent the coupled economic-climate system, which could be strongly affected by sea-level rise (e.g. Yohe and Schlesinger, 1998). RDM identifies decisions that produce good outcomes over a wide range of potential futures. Integrated assessments of the risks and strategies associated with climate change and sea-level rise often require many $\left(10^{3}-10^{6}\right)$ model runs (e.g. McInerney et al., 2011; Lempert et al., 2012), although integrated assessment can also refer to a more adaptive process actively involving stakeholders (Jakeman and Letcher, 2003).

The integrated assessments of local risks and adaptation strategies require treatments that resolve the different components of sea-level rise separately (Slangen et al., 2012), because the individual components may have quite different time scales. For example, small glaciers respond to temperature increases with a characteristic time scale of decades (Oerlemans, 2005), whereas the Greenland ice sheet has a time scale that can vary over two orders of magnitude depending on the forcing temperature (Applegate et al., 2015b). Moreover, the different components of sea-level rise have very different 'fingerprints' (distinct spatial patterns of the response; see Mitrovica et al., 2011). In particular, large mass losses from an ice sheet cause near field sea-level fall (e.g. Vermeersen and Sabadini, 1999; Mitrovica et al., 2009), even though the global mean sea level rises.

Three-dimensional models of the Greenland Ice Sheet capture many of the relevant feedbacks in the ice sheet system, but can often be too computationally expensive to include in integrated assessments. Ice sheet models track the change in mass of the ice sheet during each time step as a function of mass gain due to snowfall and mass loss due to melting and calving. 
The treatments of ice flow used in ice sheet models fall along a continuum (Kirchner et al., 2011) from the shallow ice approximation (e.g. SICOPOLIS Greve, 1997) to full-Stokes treatments (e.g. Elmer/Ice; Seddik et al., 2012), with hybrid models (e.g. Pollard and DeConto, 2012) falling in between. Full-Stokes models include all the stress components acting within the ice body, but have high computational costs, and their projections still include uncertainties due to imperfectly-known model input parameters, processes, and boundary conditions (Moore et al., 2013; Applegate et al., 2015b).

The high number of runs required for the integrated assessment of climate risks is typically computationally infeasible using the state-of-the-art three-dimensional ice sheet models. And, even with simpler one-dimensional models (e.g. GLISTEN, Haqq-Misra et al. (2012)) this task may prove too computationally demanding (Figure 1). In response, there is an active area of research that develops simpler, faster approximations of the complex systems (e.g. Oerlemans, 2003). Other approaches to reduce the computational burden include the reduction of the climatological input (e.g. Bakker et al., 2011) or the strategic subsetting of the relevant scenarios (e.g. Ntegeka et al., 2014; Van den Hurk et al., 2014).

Simplified treatments of the Greenland ice sheet include emulators (simple models of complex model output) of simulations with the state-of-the-art ice-sheet models. For example, Meehl et al. (2007; see also Irvine et al. (2012)) emulated the rate of mass loss from the GIS as a second-order polynomial function of temperature, whereas Bindschadler et al. (2013) used a linear combination of different forcings. These approaches are useful for interpolating the results from complex model simulations. They neglect, however, 
the dependence of the change rate to ice volume and are therefore less suited to project large changes.

Semi-empirical models may be better suited to guide a probabilistic assessment of potential large changes. Semi-empirical models are simple, but mechanistically motivated models of which the complexity is balanced to the availability of observational data to calibrate the model (Moore et al., 2013, e.g.). Recently, Applegate et al. (2015b) proposed a semi-empirical model that addresses both the ice sheet's potential sensitivity to ice volume changes and to temperature. The model expands on the delayed linear concept (e.g. used for global sea-level projections by Grinsted et al., 2010), in which the ice volume $V$ [m sle (meter sea-level equilivalent) $]$ is assumed to change exponentially towards a temperature-dependent equilibrium volume $V_{e q}=f(T)$ with a temperature-dependent timescale $\tau=g(T)$. A similar concept has been applied in the latest versions of the Integrated Assessment Models DICE and RICE (Dynamic/Regional Integrated model of Climate and the Economy) (Nordhaus, 2010; Nordhaus and Sztorc, 2013).

Here, we introduce a computationally efficient, physically motivated model SIMPLE (Simple Ice-sheet Model for Projecting Large Ensembles). SIMPLE can provide quite fast and arguably skillful emulations of the GIS response as simulated by the shallow ice approximation, three-dimensional ice sheet model SICOPOLIS for a wide range of warming and cooling temperature scenarios (Greenland surface temperatures $T$ between $0-12{ }^{\circ} \mathrm{C}$ relative to 1976-2005; Applegate and Keller, 2015), while its computational efficiency enables large ensembles $\left(>10^{7}\right)$ within reasonable time, even on a single computer core. 
SIMPLE expands on the work of Applegate et al. (2015b) and Nordhaus (2010). Rather than an exponential decay towards an equilibrium volume ( $\geq 0 \mathrm{~m}$ sle), SIMPLE assumes that initially the ice mass will exponentially decay towards a 'virtual equilibrium' $V_{v . e q}$ that may be lower than zero for high temperatures. The difference between the current volume and "virtual equilibrium' $\left(\Delta V_{v . e q}=V-V_{v . e q}\right)$ is interpreted as a measure for the 'imbalance' of the ice sheet that is roughly determined by snow accumulation, melt water runoff and dynamic ice flow. This concept allows the 'imbalance' that drives the ice volume change $\dot{V}$, to increase with temperature, even for temperatures that will (eventually) lead to an ice-free state $V_{e q} \approx 0$.

Section 2 introduces SIMPLE and the GIS simulations used for its development. Subsequently, we assess and compare SIMPLE to other simple representations of the GIS behaviour in section 3. Section 4 discusses SIMPLE.

\section{Methods and data}

\subsection{The SIMPLE model}

SIMPLE estimates the ice volume change $\dot{V}[\mathrm{~m}$ sle/yr $]$ from the volume $V$ [m sle $]$ and annual mean surface temperature at Greenland $T\left[{ }^{\circ} \mathrm{C}\right]$ relative to 1976-2005 by applying an exponential decay function

$$
\dot{V}=-\frac{1}{\tau}\left(\Delta V_{v \cdot e q}\right)
$$
(1)

a

Here, the difference between the ice volume and 'virtual equilibrium' $\Delta V_{v e q}=V-V_{v . e q}$ parameterizes the imbalance between mass gain due to accumulation and mass loss due to melting and calving. We refer to 'virtual' 
equilibrium because this measure may be lower than zero for high values (see Figure 2). We assume that initially the ice mass will exponentially decay towards $V_{v . e q}$ (dashed, red line), but for low ice volumes close to zero this relation is obviously not valid.

Both the timescale $\tau[\mathrm{yr}]$ and the 'virtual equilibrium' $V_{v . e q}$ are linear functions of temperature $T$,

$$
\begin{gathered}
V_{v . e q}=a T+b, \text { and } \\
\frac{1}{\tau}=\alpha T+\beta,
\end{gathered}
$$

where $a, b, \alpha$ and $\beta$ are regression coefficients. Numerical integration is used to estimate the transient GIS response to a temperature trajectory. The ice volume is prevented from reading negative values by

$$
V\left(t_{i}\right)=\max \left(0, V\left(t_{i-1}\right)+\left(t_{i}-t_{i-1}\right) \dot{V}\left(t_{i}\right)\right),
$$

where $t_{i}$ is time $[\mathrm{yr}]$ at time step $i$.

\subsection{Alternative simplified treatments}

We compare SIMPLE's ability to reproduce multiple three-dimensional ice-sheet simulations with three alternative simplified representations: i) a second-order polynomial (quadratic function), as applied by IPCC's AR4 (Meehl et al., 2007), ii) the 'delayed linear' concept as often applied to project global sea-level rise (e.g. Moore et al., 2010), iii) and the representation as applied in the integrated assessment model DICE (Nordhaus, 2010), 'GISDICE'. These three models are discussed below. 
Quadratic function. This emulator describes the ice volume change $\dot{V}$ as a quadratic function of temperature $T$,

$$
\dot{V}=a_{q}+b_{q} T+c_{q} T^{2}
$$

This approach ignores the dependence of the ice volume change $\dot{V}$ on ice volume $V$; SIMPLE simplifies to a second order polynomial (quadratic) function if $V$ is assumed to be constant in time. This means that for every $V$ the coefficients $a_{q}, b_{q}$ and $c_{q}$ of equation 5 can be exactly estimated from the SIMPLE coefficients $a, b, \alpha$ and $\beta$ (equations 1-3).

Delayed linear concept. The delayed linear concept is also a simplified version of SIMPLE in which the time-scale $\tau_{d}$ is assumed constant,

$$
\dot{V}=-\frac{1}{\tau_{d}}\left(V-a_{d} T+b_{d}\right)
$$

GIS-DICE. In contrast to the quadratic function and the delayed linear concept, GIS-DICE is slightly more complex than SIMPLE. Like, SIMPLE and the delayed linear concept, GIS-DICE also applies an exponential decay function. Yet, rather than to the 'virtual equilibrium' the volume $V$ is assumed to exponentially decay towards a physically plausible equilibrium $V_{e q}$,

$$
\dot{V}=-\frac{1}{\tau}\left(V-V_{e q}\right)
$$

47 where $V_{e q}$ and $\tau$ are (non-linear) functions of $T$,

$$
\begin{gathered}
V_{e q}=\max \left(0, a_{D} T+b_{D}\right) \\
\frac{1}{\tau}=\alpha_{D} T+\beta_{D} T^{2} .
\end{gathered}
$$




\subsection{Temperature scenarios and SICOPLIS simulations}

We calibrated SIMPLE using a large set of simulations previously performed with the ice sheet model SICOPOLIS (SImulation COde for POLythermal Ice Sheets; see Greve, 1997). SICOPOLIS is a three-dimensional ice sheet model that applies the computational efficient shallow ice approximation. This makes it attractive for studies that require long simulations such as ice sheet reconstructions, perturbed parameter ensembles or longterm projections (Applegate et al., 2012). The shallow ice approximation is, however, less suitable for short-term projections (Larour et al., 2012) because it does not represent the movement of rapid components such as ice streams and ice shelves (e.g. Kirchner et al., 2011).

The applied SICOPOLIS simulations include one 'spinup run' (Applegate et al., 2012); eight 'equilibration runs' (Applegate et al., 2015b) and twenty 'geo-engineering runs' (Applegate and Keller, 2015). A single parameter combination was used in all of these SICOPOLIS runs, corresponding to simulation \#29 from Applegate et al. (2012). This 'best' simulation achieved a modern ice volume at the end of the spinup run (described below) that is closest to the estimated modern ice volume (about $7.4 \mathrm{~m}$, Bamber et al., 2013).

I) Spinup run. The spinup simulations run from 125,000 years ago to present (Applegate et al., 2012). Modern-day ice thickness and bedrock elevation grid are applied as initial condition and the model is forced by paleo-records for temperature and sea-level and precipitation derived from the temperature record. 
II) Equilibration runs. Applegate et al. (2015b) extended the spinup simulations of the 27 'best' members of the 100-member perturbed parameter ensemble by forcing SICOPOLIS by eight instantaneous temperature increases $\left(T=0,1,2,3,4.5,6,9\right.$, and $12^{\circ} \mathrm{C}$ relative to the average $T$ from 1976 to 2005) and let it equilibrate for at least 60,000 years. We used the eight equilibration simulations with the single 'best' member.

III) Geo-engineering scenarios. Applegate and Keller (2015) used the single 'best' member to extend the spinup simulations by 20 geo-engineered temperature trajectories (Figure 3 ). Those $T$ trajectories were obtained by adjusting a base scenario (black line, Figure 3) derived from a simulation with the intermediate-complexity climate model CLIMBER-3a (Schewe et al., 2011) following the Representative Concentration Pathway RCP8.5 (Moss et al., 2010). The scenarios distinguish two geo-engineering strategies that start at ten different years $(2025,2075, \ldots, 2475)$. In the 'temperature stabilization' scenarios, the base scenario is leveled off at the temperature anomaly reached at that year (colored dots, Figure 3). In the 'gradual draw-down', the temperature anomaly is rapidly forced down to zero at a rate of $0.1{ }^{\circ} \mathrm{C} / \mathrm{yr}$.

\subsection{Emulation of SICOPOLIS: calibration and cross-validation}

We calibrate the parameters of SIMPLE and the other emulators we compare SIMPLE to by minimizing the RMSE (Root Mean Squared Error) of the emulated change $\dot{V}_{\text {em }}$ in response to $T$ and $V_{\text {SIC }}$ as simulated with SICOPOLIS. We do this on the basis of the complete set of geo-engineering scenarios and several cross-validation subsets (Table 1, see subsection 3.3). The crossvalidation provides insight into the model's sensitivity to 'over-fitting'. Good 
cross-validation results may increase the confidence in simulated response outside the calibrated range, i.e. predictive ability (see Rao and $\mathrm{Wu}, 2001$ ). 'L1O' consists of 20 subsets that leave one scenario out for calibration and compares the calibrated model to the SICOPOLIS results from the one left-out scenario. 'L4O' consists of five subsets leaving 4 scenarios out, based on the starting year of the geo-engineering and 'L5O' exists of four subsets leaving 5 scenarios out.

Table 1: Scenarios that are left out of the different cross-validation subsets. 'L1O', 'L4O' and 'L5O' refer to the different cross-validation strategies that leave 1, 4 and 5 scenarios out. 'st' and 'dd' respectively refer to the temperature 'stabilization' and 'draw-down' geo-engineering strategies and the first column refers to the starting year of the geoengineering.

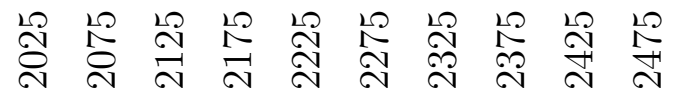

\begin{tabular}{|c|c|c|c|c|c|c|c|c|c|c|c|}
\hline \multirow{2}{*}{ L10 } & \multirow{2}{*}{$\begin{array}{l}\text { temperature stabilization } \\
\text { temperature draw-down }\end{array}$} & 1 & 1 & 1 & 1 & 1 & 1 & 1 & 1 & 1 & 1 \\
\hline & & 1 & 1 & 1 & 1 & 1 & 1 & 1 & 1 & 1 & 1 \\
\hline L40 & $\begin{array}{l}\text { temperature stabilization } \\
\text { temperature draw-down }\end{array}$ & \multicolumn{2}{|c|}{4} & \multicolumn{2}{|c|}{4} & \multicolumn{2}{|c|}{4} & \multicolumn{2}{|c|}{4} & \multicolumn{2}{|c|}{4} \\
\hline \multirow{2}{*}{ L50 } & \multirow{2}{*}{$\begin{array}{l}\text { temperature stabilization } \\
\text { temperature draw-down }\end{array}$} & \multicolumn{5}{|c|}{5} & \multicolumn{5}{|c|}{5} \\
\hline & & \multicolumn{5}{|c|}{5} & \multicolumn{5}{|c|}{5} \\
\hline
\end{tabular}

\section{Results}

\section{1. 'Virtual equilibrium'}

The ice volume change $\dot{V}$ clearly increases with the distance to the "virtual equilibrium' $\Delta V_{v . e q}=V-V_{v . e q}$, for all time steps of all simulations as 
introduced in subsection 2.3 (Figure 4). SIMPLE applies the concept of "virtual equilibrium' volume that, in contrast to the equilibrium, is not bounded by a zero volume. This allows for an increasing imbalance $\left(\Delta V_{v . e q}\right)$ with temperature, also for all temperatures that will (eventually) lead to an ice-free state, i.e. $V_{e q} \approx 0 \mathrm{~m}$ sle. In case of equal $\Delta V_{v . e q}$, the ice volume change $\dot{V}$ is generally lower for higher ice volume $V$ (dark blue). Yet, for ice volumes $V$ close to or lower than 1 meter sle (bright green), the ice volume change is much lower because reduced ice sheet surface available for melting and reduced efficiency of melt water runoff and ice flow.

\subsection{Time-scale}

The SICOPOLIS runs show a clear dependency of the time-scale $\tau$ on temperature (Figure 5, see also Applegate et al. (2015b)). This observation explains the curvature of the relation between $\Delta V_{v . e q}$ and $\dot{V}$ (Figure 4), in that $\Delta V_{v . e q}$ is largely determined by temperature. The "exponential change rate' $\frac{1}{\tau}=-\frac{\dot{V}}{\Delta V_{v . e q}}$ increases with temperature. For the $T$ range $0-12^{\circ} \mathrm{C}$, this relation is well approximated by equation 3 .

\subsection{Transient response}

SIMPLE reproduces the SICOPOLIS simulated transient GIS response to the geo-engineering scenarios more tightly than the other three simple models that we tested (Figure 6$)$. The quadratic function $\left(\dot{V}=a_{q}+b q T+c_{q} T^{2}\right)$ ignores the dependence on ice volume $V$. In the delayed linear concept as used for global sea-level projections (e.g. Moore et al., 2010; Grinsted et al., 2010), the ice volume change $\dot{V}$ does depend on volume $V$, but the constant time-scale $\tau$ results in a decay rate biased to the average. This constant 
time-scale results, for example, in too high regrowth rates in the temperature draw-down geoengineering scenarios (second row of panels).

The GIS model used in DICE (Nordhaus, 2010) largely solves this problem by describing the change rate as a quadratic function of temperature $\left(\frac{1}{\tau}=\right.$ $\left.\alpha_{D} T+\beta_{D} T^{2}\right)$. However, this model's use of an equilibrium volume that is bounded by zero $\left(V_{e q}=\max \left(0, a_{D} T+b_{D}\right)\right)$ causes an underestimation of the imbalance of the ice sheet at high temperatures, resulting in too low ice volume change rates. This discrepancy is most pronounced in case of relatively low ice volumes (Figure 6, red colors). SIMPLE addresses this problem by applying the distance to the 'virtual equilibrium' $\Delta V_{v . e q}$ as a measure of the imbalance. This enables an improved reproduction of the simulated GIS behavior (lower panels) even though SIMPLE is based on simpler algorithmic methods than DICE-GIS.

\subsection{Cross-validation}

The four simple models differ in terms of structure and complexity. One robust and simple approach to assess the appropriateness of the model structure and complexity is to analyze the cross-validation errors (e.g. Schoups et al., 2008). We quantified the ability of the model to mimic the simulated transient GIS response on the basis of the RMSE, applying three different cross-validation strategies. Other common measures to evaluate model performance are, in our particular case, hard to interpret. We do not consider the fraction explained variance because the SICOPOLIS runs we wish to emulate show largely monotonic decreasing trends, which would give too much weight to the scenarios that do show a clear change of direction. Also autocorrelation of the emulator error is hard to interpret since we are dealing 
with a strongly autocorrelated process and model. A serially correlated error would rapidly accumulate to large errors.

SIMPLE outperforms the other tested simple models in terms of crossvalidation RMSE (Figure 7). The figure shows the RMSE as a function of evaluation length of the transient scenarios for the four simple models (colors) trained on the complete set of scenarios (dots), and three crossvalidation strategies (L1O: triangles, L4O: squares, L5O: crosses). SIMPLE and GIS-DICE outperform the quadratic function and delayed linear concept by about a factor 4 , regardless of the year until which the future emulation is evaluated. SIMPLE has a 20-30\% lower RMSE than GIS-DICE.

In general, the different cross-validation strategies provide very similar RMSE estimates as when all scenarios are used to calibrate the different models. GIS-DICE, however, shows considerably higher RMSE for the L5O cross-validation, indicating a higher sensitivity to the training set. This difference in RMSE given the cross-validation data sets may be the result of the slightly more complex structure of GIS-DICE compared to SIMPLE.

\section{Discussion}

SIMPLE is a computationally very efficient (see figure 1) 4-parameter, physically motivated model that describes the GIS volume change $\dot{V}$ as a linear function of current volume $V$ and surface temperature $T$ forcing. SIMPLE displays very similar change direction-dependent behavior as SICOPO-

LIS (figure 8) and SIMPLE skillfully emulates the transient GIS response to a wide range of temperature forcings as simulated by the three-dimensional ice sheet model SICOPOLIS (Figure 6). It may be utilized to evaluate simu- 
lations with complex process-based ice sheet models like earlier done on the basis of the delayed linear concept (Applegate et al., 2015b). Yet, it is especially designed to allow for the large numbers of simulations necessary for integrated assessments, Many-Objective Robust Decision Making (Kasprzyk et al., 2013; Singh et al., 2015) and the exploration of model parameter uncertainty.

One might argue that SIMPLE has been developed and validated on the basis of simulations with the shallow ice approximation model SICOPOLIS, that neglects important stress components and therefore is unable to represent faster components. Yet, the incorporation of higher order physics may not necessarily change the overall GIS response by much (Applegate et al., 2015b). It can be argued that the relatively high efficiency of SICOPOLIS is beneficial for some analysis. For example, this feature allowed several studies (e.g. Applegate et al., 2012, 2015b; Applegate and Keller, 2015) to produce a very large ensemble of GIS simulations. The use of large ensembles can be important to test a model over wide range of forcings.

Nevertheless, these higher-order components may affect the ice sheet response and it is worthwhile to calibrate (and test) SIMPLE using runs from more complete, process-based models. This additional calibration may identify the need to adjust equations 2 and 3 to estimate $V_{v e q}$ and $\tau$. This can be done following a similar approach as presented in this paper by simply adjusting the presented linear equations 2 and 3. More drastic changes to SIMPLE are not necessarily required since the ignored processes by SICOPOLIS are also largely controlled by the Greenland temperature.

Overall, we conclude that SIMPLE is a physically motivated model that 
305

performs well and is suited for many applications.

\section{Author contributions}

K. Keller and P.J. Applegate initiated the study. K. Keller and A.M.R. Bakker designed the research. P.J. Applegate processed the SICOPOLIS model output and A.M.R. Bakker coded the simple models, carried out the model emulations, processed the model output, made the figures, and wrote the first draft of the manuscript.

\section{Acknowledgements}

This work was partially supported by the National Science Foundation through the Network for Sustainable Climate Risk Management (SCRiM) under NSF cooperative agreement GEO-1240507 and the Penn State center for Climate Risk Management.

\section{Appendix A. Additional figures}

\section{Appendix B. R-function of SIMPLE}

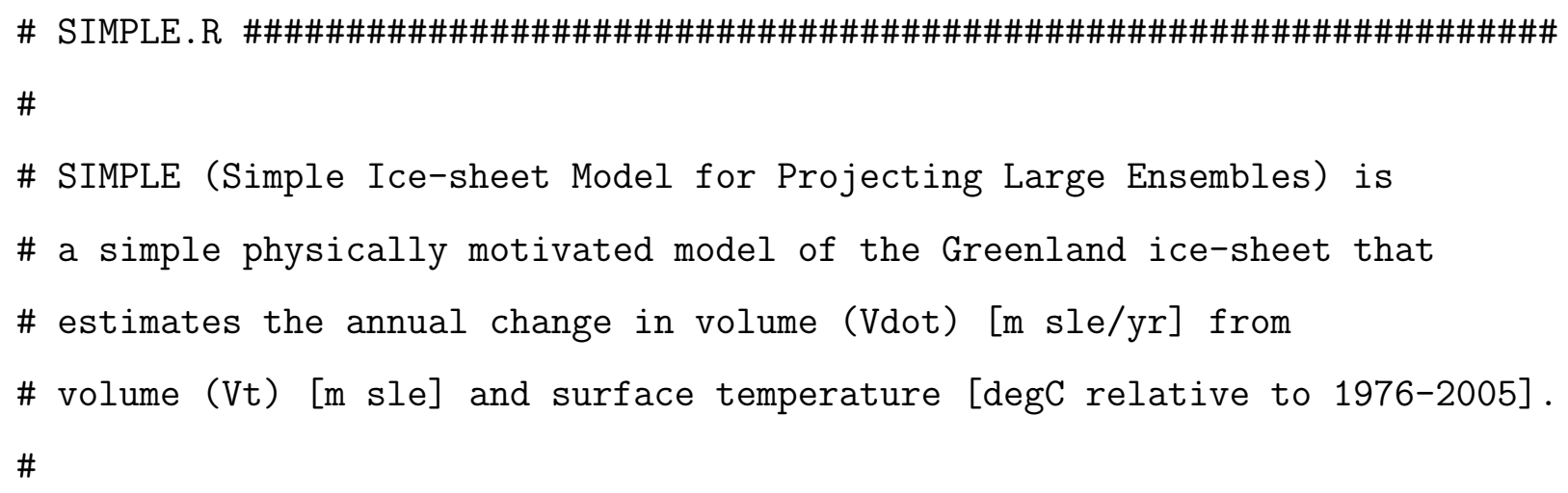


\# (Bakker, A.M.R. and P.J. Applegate, and K. Keller, 2016. "A simple, \# physically motivated model of sea-level contributions from the

\# Greenland Ice Sheet in response to temperature changes")

\#

\# variables needed

\# params: numeric vector containing 'a', 'b', 'alpha' and 'beta'

\# default values from Bakker et al. (2016)

\# Tt: numeric vector or matrix containing annual mean temperature

\# Vt: numeric vector or matrix containing current ice volume

\# V0: numeric with initial ice volume [m sle]

\#

\# Copyright (C) 2016 Alexander Bakker

\#

\# SIMPLE.R is free software: you can redistribute it and/or modify

\# it under the terms of the GNU Lesser General Public License as published by

\# the Free Software Foundation, either version 3 of the License, or (at your

\# option) any later version.

$\#$

\# SIMPLE.R is distributed in the hope that it will be useful, but

\# WITHOUT ANY WARRANTY; without even the implied warranty of MERCHANTABILITY

\# or FITNESS FOR A PARTICULAR PURPOSE. See the GNU Lesser General Public

\# License for more details.

\#

\# You should have received a copy of the GNU Lesser General Public License

\# along with the SIMPLE code. If not, see <http://www.gnu.org/licenses/ 
370

374

375

\# Volume change from Volume and Temperature

SIMPLE_Vdot <- function (

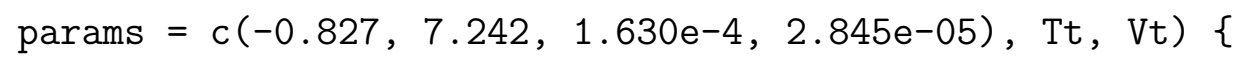

\# Extract the parameters from the vector params.

a $\quad=\operatorname{params}[1]$

$\mathrm{b}=\operatorname{params}[2]$

alpha $=$ params [3]

beta $=$ params $[4]$

\# model

Veq $<-\mathrm{a} * \mathrm{Tt}+\mathrm{b}$

\# 'virtual' equilibrium

tau $<-1 /$ (alpha $*$ Tt + beta) \# time scale

Vdot <- - (Vt-Veq)/tau

\# annual change in volume

return (Vdot)

\}

\# Transient volume response from Temperature and initial volume

SIMPLE_traject $=$ function $($ params $=c(-0.827,7.242,1.630 \mathrm{e}-4,2.845 \mathrm{e}-05)$, V0, Tt $)$

\# Extract the parameters from the vector params.

a $\quad=\operatorname{params}[1]$

$\mathrm{b} \quad=\operatorname{params}[2]$ 


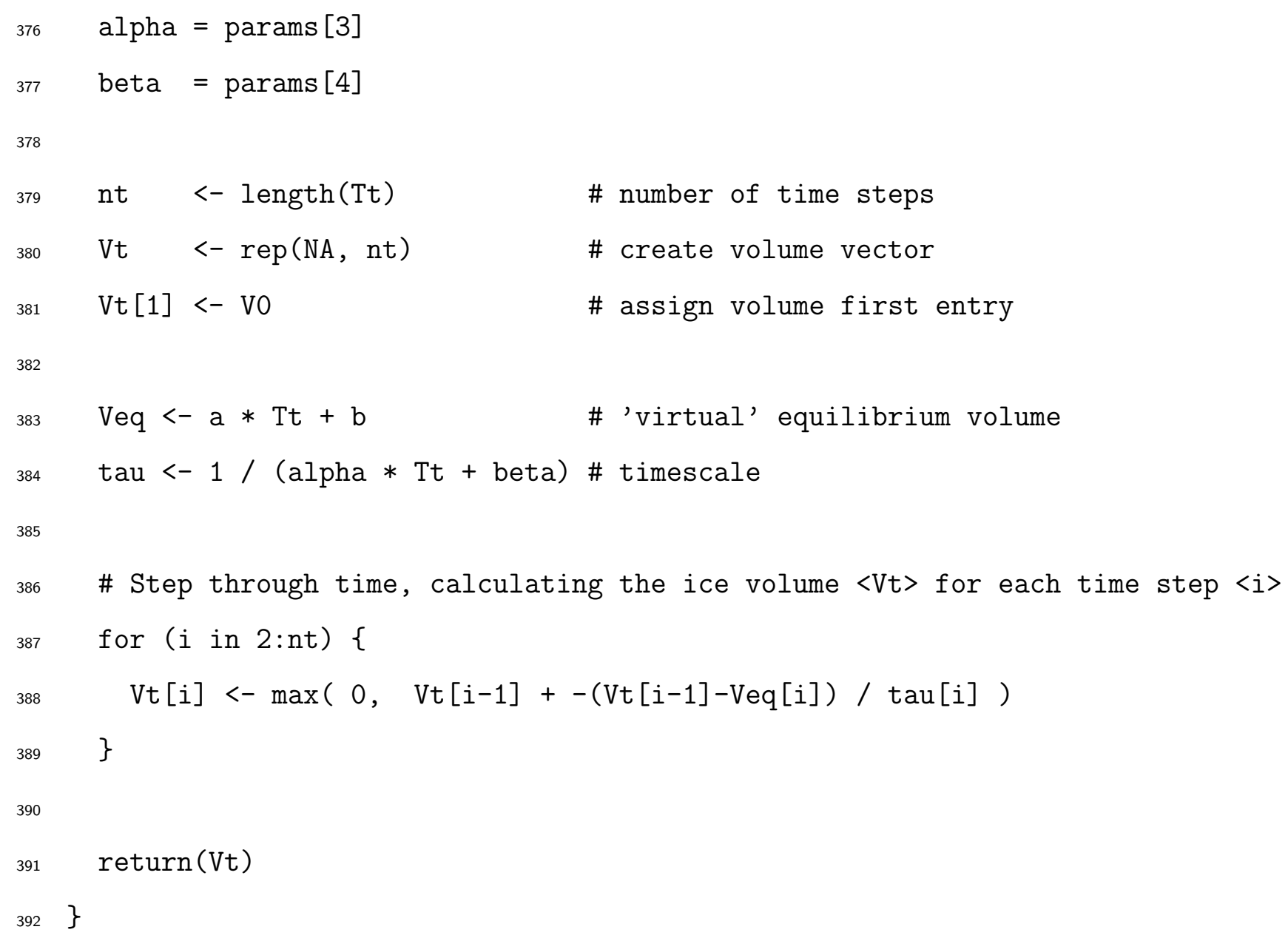

376

$376 \quad$ alpha $=$ params $[3]$
$377 \quad$ beta $=$ params $[4]$

378

379

380

381

382

383

384

385

386

387

388

389

390

391

392

nt $\quad<-$ length (Tt)

Vt $<-\operatorname{rep}(\mathrm{NA}, \mathrm{nt})$

Vt $[1]<-$ V0

Veq $<-\mathrm{a} * \mathrm{Tt}+\mathrm{b}$

tau $<-1 /$ (alpha * Tt + beta) \# timescale

\# Step through time, calculating the ice volume <Vt> for each time step <i> for (i in $2: n t)\{$

$\operatorname{Vt}[i]<-\max (0, \quad \mathrm{Vt}[\mathrm{i}-1]+-(\mathrm{Vt}[\mathrm{i}-1]-\mathrm{Veq}[\mathrm{i}]) / \operatorname{tau}[\mathrm{i}])$

\}

$\operatorname{return}(\mathrm{Vt})$

\}

393

394

\section{Bibliography}

Applegate, P. J., Keller, K., 2015. How effective is albedo modification (solar radiation management geoengineering) in preventing sea-level rise from the Greenland Ice Sheet? Environmental Research Letters 10 (8), 084018, DOI: $10.1007 / \mathrm{s} 00382-014-2451-7$.

Applegate, P. J., Kirchner, N., Stone, E. J., Keller, K., Greve, R., 2012. An assessment of key model parametric uncertainties in projections of Green- 
land Ice Sheet behavior. The Cryosphere 6, 589-606, DOI: 10.5194/tc-6589-2012.

Applegate, P. J., Parizek, B. R., Nicholas, R. E., Alley, R. B., Keller, K., 2015b. Increasing temperature forcing reduces the Greenland Ice Sheet's response time scale. Climate Dynamics 45 (7), 2001-2011, DOI: 10.1007/s00382-014-2451-7.

Bakker, A. M. R., van den Hurk, B. J. J. M., Bessembinder, J. J. E., Kroon, T., 2011. Standard years for large-scale hydrological scenario simulations. Environmental Modelling and Software 26 (6), 797-803, DOI: 10.1016/j.envsoft.2010.11.008.

Bamber, J. L., Griggs, J. A., Hurkmans, R. T. W. L., Dowdeswell, J. A., Gogineni, S. P., Howat, I., Mouginot, J., Paden, J., Palmer, S., Rignot, E., Steinhage, D., 2013. A new bed elevation dataset for Greenland. The Cryosphere 7, 499-510, DOI: 10.5194/tc-7-499-2013.

Bindschadler, R. A., Nowicki, S., Abe-Ouchi, A., Aschwanden, A., Choi, H., Fastook, J., Granzow, G., Greve, R., Gutowski, G., Herzfeld, U., Jackson, C., Johnson, J., Khroulev, C., Levermann, A., Lipscomb, W. H., Martin, M. A., Morlighem, M., Parizek, B. R., Pollard, D., Price, S. F., Ren, D., Saito, F., Sato, T., Seddik, H., Seroussi, H., Takahashi, K., Walker, R., Wang, W. L., 2013. Ice-sheet model sensitivities to environmental forcing and their use in projecting future sea level (the SeaRISE project). Journal of Glaciology 59 (214), 195-224, DOI: 10.3189/2013JoG12J125.

Church, J. A., Clark, P. U., Cazenave, A., Gregory, J. M., Jevrejeva, S., 
Levermann, A., Merrifield, M. A., Milne, G. A., Nerem, R. S., Nunn, P. D., Payne, A. J., Pfeffer, W. T., Stammer, D., Unnikrishnan, A. S., 2013. Sea level change. In: Stocker, T. F., Qin, D., Plattner, G.-K., Tignor, M., Allen, S. K., Boschung, J., Nauels, A., Xia, Y., Bex, V., Midgley, P. M. (Eds.), Climate Change 2013: The Physical Science Basis. Contribution of Working Group I to the Fifth Assessment Report of the Intergovernmental Panel on Climate Change. Cambridge University Press, Cambridge, United Kingdom and New York, NY, USA, pp. 1137-1216.

Greve, R., 1997. Application of a polythermal three-dimensional ice sheet model to the greenland ice sheet: Response to steady-state and transient climate scenarios. Journal of Climate 10 (5), 901-918, DOI: 10.1175/15200442(1997)010;0901:AOAPTD ¿2.0.CO;2.

Grinsted, A., Moore, J. C., Jevrejeva, S., 2010. Reconstructing sea level from paleo and projected temperatures 200 to 2100 AD. Climate Dynamics 34 (4), 461-472, DOI: 10.1007/s00382-008-0507-2.

Hadka, D., Herman, J., Reed, P., Keller, K., 2015. An open source framework for many-objective robust decision making. Environmental Modelling \& Software 74, 114-129, DOI: 10.1016/j.envsoft.2015.07.014.

Hall, J. W., Lempert, R. J., Keller, K., Hackbarth, A., Mijere, C., McInerney, D. J., 2012. Robust climate policies under uncertainty: A comparison of robust decision making and info-gap methods. Risk Analysis 32 (10), 16571672, DOI: 10.1111/j.1539-6924.2012.01802.x.

Haqq-Misra, J., Applegate, P., Tuttle, B., Nicholas, R., Keller, K., 2012. A 
computationally efficient model for the greenland ice sheet. The Cryosphere Discussions 6, 2751-2788, DOI: 10.5194/tcd-6-2751-2012.

Irvine, P. J., Sriver, R. L., Keller, K., 2012. Tension between reducing sealevel rise and global warming through solar-radiation management. Nature Climate Change 2 (2), 97-100, DOI: 10.1038/nclimate1351.

Jakeman, A. J. and Letcher, R. A., 2003. Integrated assessment and modelling: features, principles and examples for catchment management. Environmental Modelling \& Software 18, 491-501, DOI: 10.1016/S13648152(03)00024-0.

Kasprzyk, J. R., Nataraj, S., Reed, P. M., Lempert, R. J., 2013. Many objective robust decision making for complex environmental systems undergoing change. Environmental Modelling \& Software 42, 55-71, DOI: 10.1016/j.envsoft.2012.12.007.

Kirchner, N., Hutter, K., Jakobsson, M., Gyllencreutz, R., 2011. Capabilities and limitations of numerical ice sheet models: a discussion for Earthscientists and modelers. Quaternary Science Reviews 30 (25-26), 36913704, DOI: 10.1016/j.quascirev.2011.09.012.

Larour, E., Seroussi, H., Morlighem, M., Rignot, E., 2012. Continental scale, high order, high spatial resolution, ice sheet modeling using the Ice Sheet System Model (ISSM). Journal of Geophysical Research 117 (F1), F01022, DOI: 10.1029/2011JF002140.

Lempert, R., Sriver, R. L., Keller, K., 2012. Characterizing uncertain sea level 
rise projections to support investment decisions. Tech. Rep. Publication Number: CEC-500-2012-056, California Energy Commission.

Lempert, R. J., Popper, S. W., Bankes, S. C., 2003. Shaping the next one hundred years: New methods for quantitative, long-term policy analysis. Tech. Rep. MR-1626-RPC, RAND Corporation, Santa Monica, CA, USA.

Lenton, T. M., Held, H., Kriegler, E., Hall, J. W., Lucht, W., Rahmstorf, S., Schellnhuber, H. J., 2008. Tipping elements in the Earth's climate system. Proceedings of the National Academy of Sciences of the United States of America (PNAS) 105 (6), 1786-1793, DOI: 10.1073/pnas.0705414105.

McInerney, D., Lempert, R., Keller, K., 2011. What are robust strategies in the face of uncertain climate threshold responses? Climatic Change 112 (3-4), 547-568, DOI: 10.1007/s10584-011-0377-1.

Meehl, G. A., Stocker, T. F., Collins, W. D., Friedlingstein, P., Gaye, A. T., Gregory, J. M., Kitoh, A., Knutti, R., Murphy, J. M., Noda, A., Raper, S. C. B., Watterson, I. G., Weaver, A. J., Zhao, Z.-C., 2007. Global climate projections. In: Solomon, S., Qin, D., Manning, M., Chen, Z., Marquis, M., Averyt, K. B., Tignor, M., Miller, H. L. (Eds.), Climate Change 2007: The Physical Science Basis. Contribution of Working Group I to the Fourth Assessment Report of the Intergovernmental Panel on Climate Change. Cambridge University Press, Cambridge, United Kingdom and New York, NY, USA, pp. 747-845.

Mitrovica, J. X., Gomez, N., Morrow, E., Hay, C., Latychev, K., Tamisiea, M. E., 2011. On the robustness of predictions of sea level fingerprints. 
Geophysical Journal International 187 (2), 729742, DOI: 10.1111/j.1365246X.2011.05090.x.

Mitrovica, J. X., Gomez, N., U., C. P., 2009. The sea-level fingerprint of West Antarctic collapse. Science 323 (5915), 753, DOI: 10.1126/science.1166510.

Moore, J. C., Grinsted, A., Zwinger, T., Jevrejeva, S., 2013. Semiempirical and process-based global sea level projections. Reviews of Geophysics 51 (3), 484-522, DOI: 10.1002/rog.20015.

Moore, J. C., Jevrejeva, S., Grinsted, A., 2010. Efficacy of geoengineering to limit 21st century sea-level rise. Proceedings of the National Academy of Sciences of the United States of America (PNAS) 107 (36), 15699-15703, DOI: $10.1073 /$ pnas.1008153107.

Moss, R. H., Edmonds, J. A., Hibbard, K. A., Manning, M. R., Rose, S. K., van Vuuren, D. P., Carter, T. R., Emori, S., Kainuma, M., Kram, T., Meehl, G. A., Mitchell, J. F. B., Nakićenović, N., Riahi, K., Smith, S. J., Stouffer, R. J., Thomson, A. M., Weyant, J. P., Wilbanks, T. J., 2010. The next generation of scenarios for climate change research and assessment. Nature 463, 747-756, DOI: 10.1038/nature08823.

Nordhaus, W., 2008. A question of balance; Weighing the Options on Global Warming Policies. Yale University Press, New Haven and London.

Nordhaus, W., Sztorc, P., 2013. DICE 2013: Introduction and user's manual, second edition.

URL http://www.econ.yale.edu/ nordhaus/homepage/documents/ DICE \_Manual\_103113r2.pdf 
Nordhaus, W. D., 2010. Projections of Sea Level Rise (SLR). Yale university. URL http://www.econ.yale.edu/ nordhaus/homepage/documents/ SLR \_021910.pdf

Ntegeka, V., Baguis, P., Roulin, E., Willems, P., 2014. Developing tailored climate change scenarios for hydrological impact assessments. Journal of Hydrology 508, 307-321, DOI: 10.1016/j.jhydrol.2013.11.001.

Oerlemans, J., 2003. A quasi-analytical ice-sheet model for climate studies. Nonlinear Processes in Geophysics 10 (4-5), 441-452, DOI: 10.5194/npg10-441-2003.

Oerlemans, J., 2005. Extracting a climate signal from 169 glacier records. Science 308 (5722), 675-677, DOI: 10.1126/science.1107046.

Pollard, D., DeConto, R. M., 2012. Description of a hybrid ice sheet-shelf model, and application to Antarctica. Geoscientific Model Development 5, 1273-1295, DOI: 10.5194/gmd-5-1273-2012.

Rao, C. R., Wu, Y., 2001. On Model Selection. IMS Lecture Notes - Monograph Series 38 (Model Selection (2001)), 1-64.

Robinson, A., Calov, R., Ganopolski, A., 2012. Multistability and critical thresholds of the Greenland ice sheet. Nature Climate Change 2, 429-432, DOI: $10.1038 /$ nclimate1449.

Rogozhina, I., Martinec, Z., Hagedoorn, J. M., Thomas, M., Fleming, K., 2011. On the long-term memory of the Greenland Ice Sheet. Journal of Geophysical Research 116 (F01011), DOI: 10.1029/2010JF001787. 
Schewe, J., Levermann, A., Meinshausen, M., 2011. Climate change under a scenario near $1.5^{\circ} \mathrm{C}$ of global warming: monsoon intensification, ocean warming and steric sea level rise. Earth System Dynamics 2, 25-35, DOI: 10.5194/esd-2-25-2011.

Schoups, G., van de Giesen, N. C., Savenije, H. H. G., 2008. Model complexity control for hydrologic prediction. Water resources research 44 (W00B03), DOI: $10.1029 / 2008$ WR006836.

Seddik, H., Greve, R., Zwinger, T., Gillet-Chaulet, F., Gagliardini, O., 2012. Simulations of the Greenland ice sheet 100 years into the future with the full Stokes model Elmer/Ice. Journal of Glaciology 58 (209), 427-440, DOI: 10.3189/2012JoG11J177.

Singh, R., Reed, P. M., Keller, K., 2015. Many-objective robust decision making for managing an ecosystem with a deeply uncertain threshold response. Ecology and Society 20 (3), 12, DOI: 10.5751/ES-07687-200312.

Slangen, A. B. A., Katsman, C. A., van de Wal, R. S. W., Vermeersen, L. L. A., Riva, R. E. M., 2012. Towards regional projections of twentyfirst century sea-level change based on IPCC SRES scenarios. Climate Dynamics 38 (5), 1191-1209, DOI: 10.1007/s00382-011-1057-6.

van den Hurk, B., Siegmund, P., Klein Tank (Eds.), A., Attema, J., Bakker, A., Beersma, J., Bessembinder, J., Boers, R., Brandsma, T., van den Brink, H., Drijfhout, S., Eskes, H., Haarsma, R., Hazeleger, W., Jilderda, R., Katsman, C., Lenderink, G., Loriaux, J., van Meijgaard, E., van Noije, T., van Oldenborgh, G. J., Selten, F., Siebesma, P., Sterl, A., de Vries, H., 
van Weele, M., de Winter, R., Zadelhoff, G.-J., 2014. KNMI'14: Climate Change scenarios for the 21st Century - A Netherlands perspective. Scientific Report WR2014-01, KNMI, De Bilt, the Netherlands.

URL http://www.knmi.nl/bibliotheek/knmipubWR/WR2014-01.pdf

Vermeersen, L. L. A., Sabadini, R., 1999. Polar wander, sea-level variations and ice age cycles. Surveys in Geophysics 20 (5), 415-440, DOI: 10.1007/s00382-012-1471-4.

Yohe, G. W., Schlesinger, M. E., 1998. Sea-Level Change: The Expected Economic Cost of Protection Or Abandonment in the United States. Climatic Change 38 (4), 447-472, DOI: 10.1023/A:1005338413531. 


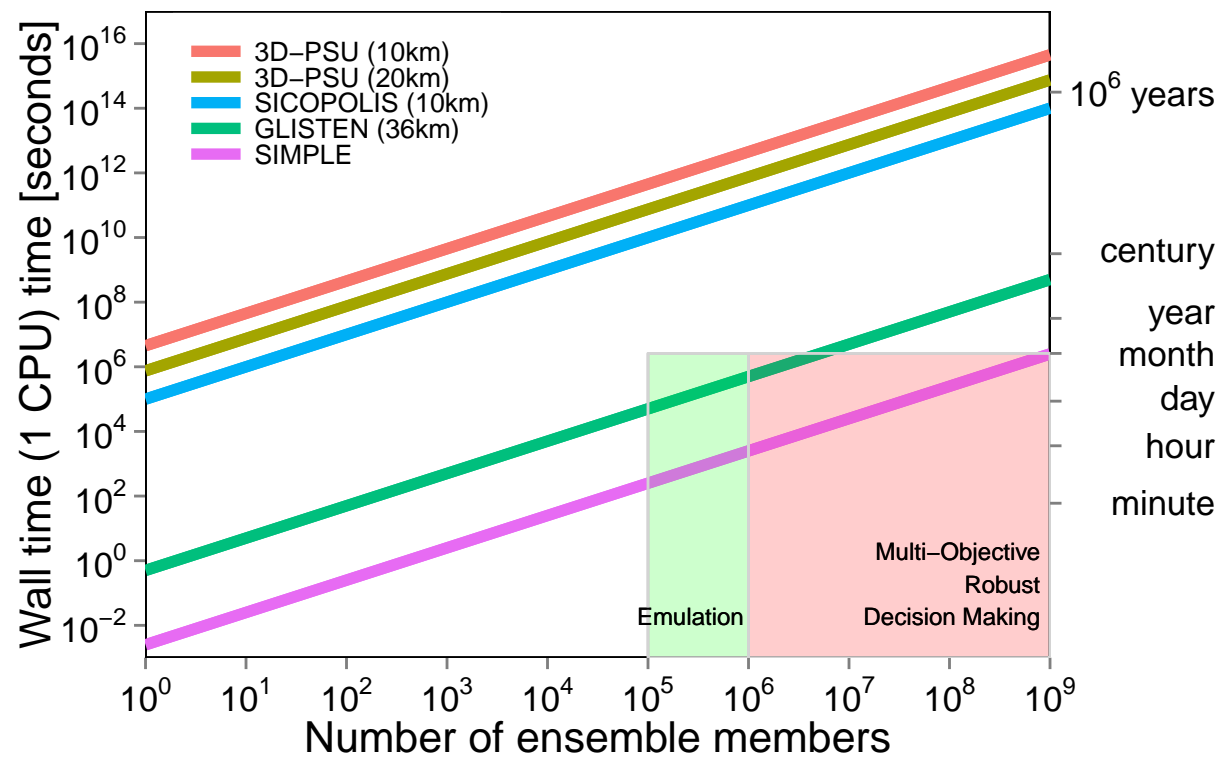

Figure 1: Approximate estimates of the computing time required for various numbers of model runs using a hierarchy of models (colored lines), assuming that only one processor is available to perform the calculations. Computing times for 125,000-yr simulations are shown because ice sheet models must be 'spun up' over at least this much time for every unique parameter combination (Rogozhina et al., 2011; Applegate et al., 2012; HaqqMisra et al., 2012). The colored boxes mark the zones that achieve the minimum number of simulations required for Integrated Assessment studies ( $>10^{5}$, green; e.g McInerney et al. (2011)) and for Multi-Objective Robust Decision Making (MORDM) (>10 ${ }^{6}$, red; Kasprzyk et al. (2013); Singh et al. (2015)) within a computation time of one month. Three-dimensional ice sheet models such as the PSU-3D ice sheet model (Pollard and DeConto, 2012), which includes 'hybrid' ice dynamics, and SICOPOLIS (Greve, 1997), which is a Shallow-Ice Approximation model, are clearly too computationally expensive to achieve these numbers of simulations in a reasonable time. One-dimensional models such as GLISTEN (Haqq-Misra et al., 2012) may be more appropriate for IAM studies from a computational perspective; however, SIMPLE, which we describe here, is about two orders of magnitude faster than GLISTEN. 

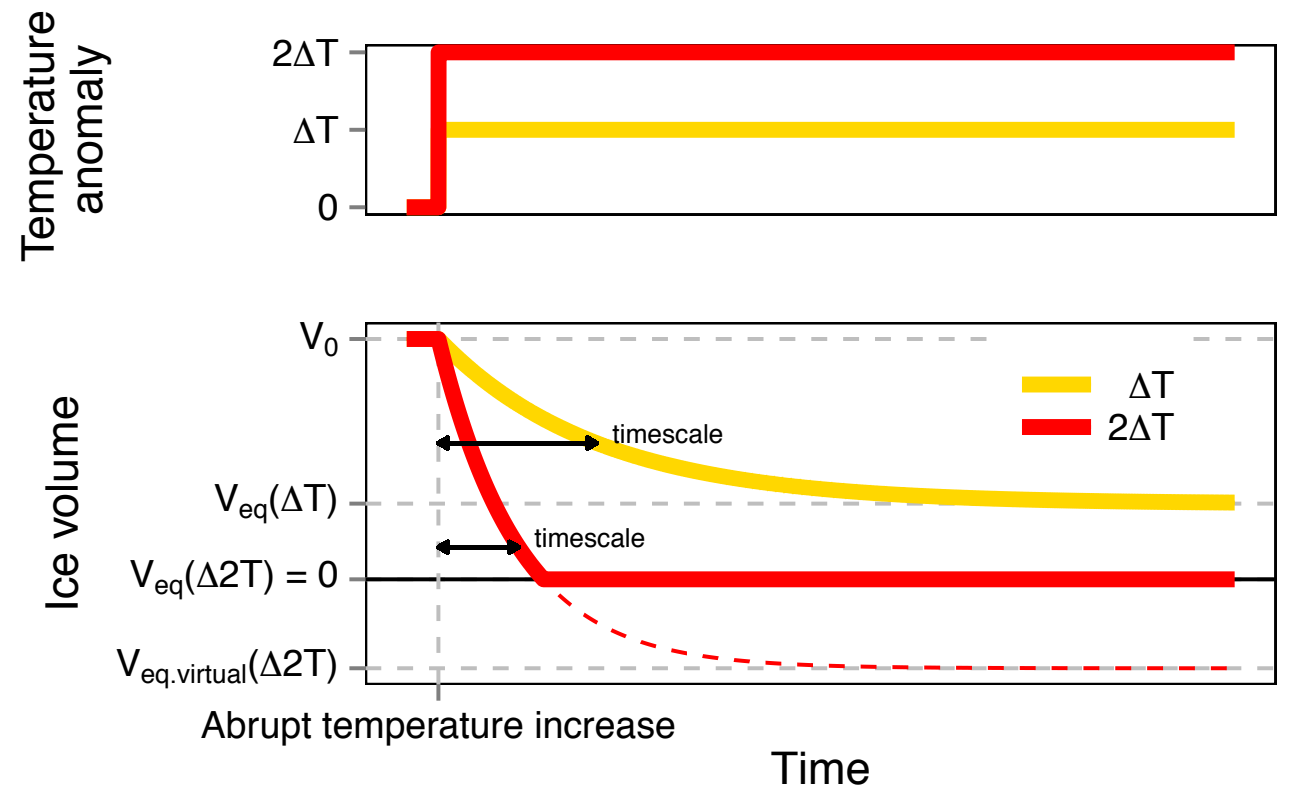

Figure 2: Response of Greenland Ice Sheet volume (lower panel) to moderate ( $\Delta T$, orange) and high $(2 \Delta T$, red) instantaneous temperature increase (upper panel) from system that is initially in equilibrium $V=V_{0}$ as simulated by SIMPLE (equations 1-3). 


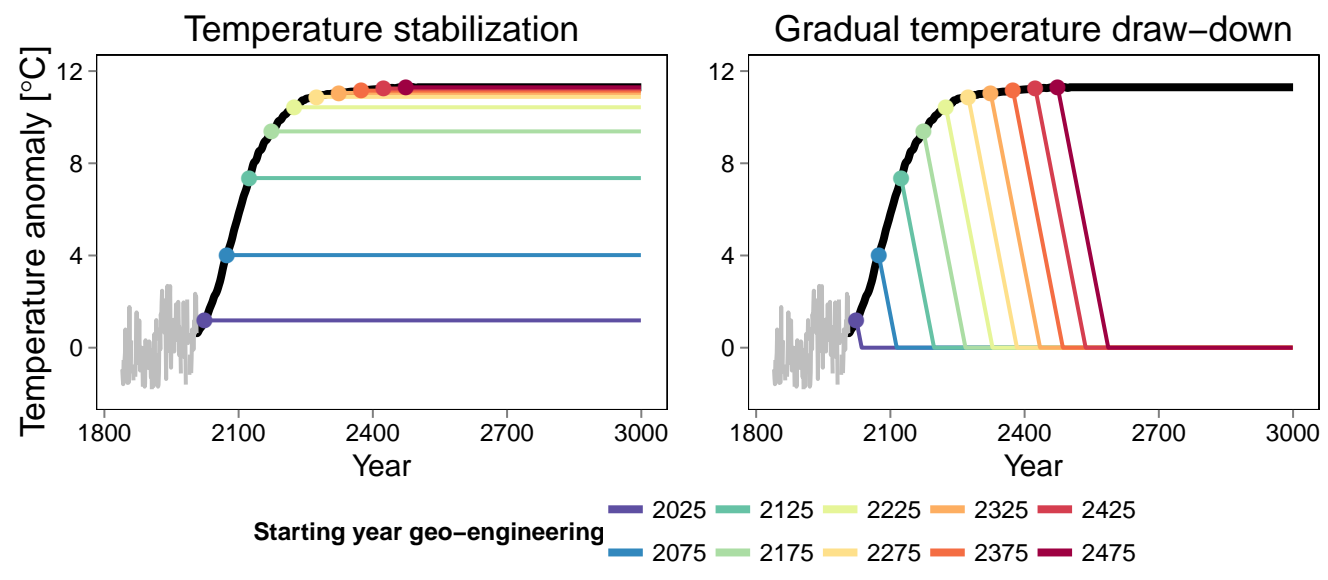

Figure 3: Projected Greenland surface temperature for rcp8.5 (Schewe et al., 2011, black line) together with 20 geo-engineering scenarios. Upper panel, 'temperature stabilization' scenarios; lower panel, 'gradual temperature draw-down' scenarios. Different colors indicate different starting years (dots) for geo-engineering. Gray line, observed temperatures. Replotted from Applegate and Keller (2015). 


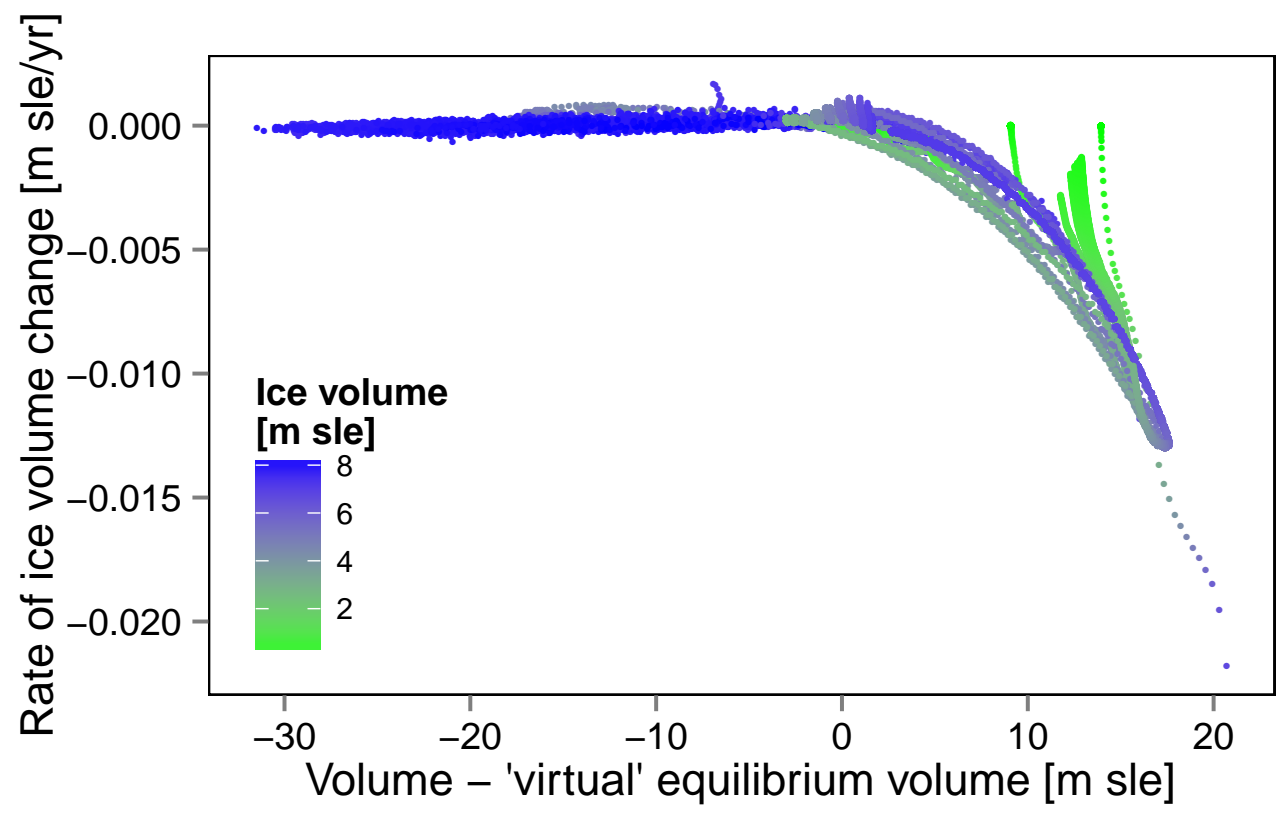

Figure 4: Rate of ice volume change $\dot{V}$ as a function of the distance to the "virtual equilibrium' ice volume $\Delta V_{v . e q}=V-V_{v . e q}$ derived from different simulations with SICOPOLIS; 125ka spinup run (Applegate et al., 2012), 8 equilibrium runs (Applegate et al., 2015b) and RCP8.5 and 20 geo-engineering runs (Applegate and Keller, 2015). Here, $V_{v . e q}$ is estimated with equation 2 applying $a=-1.62$ and $b=5.56$, based on a linear regression through the equilibria as simulated by Applegate et al. (2015b). Colors refer to SICOPOLIS ice volume. The rate of mass loss clearly increases with distance to 'virtual equilibrium', whereas the growing rate seems always small. In similar figure (A.9) colors refer to model runs. 


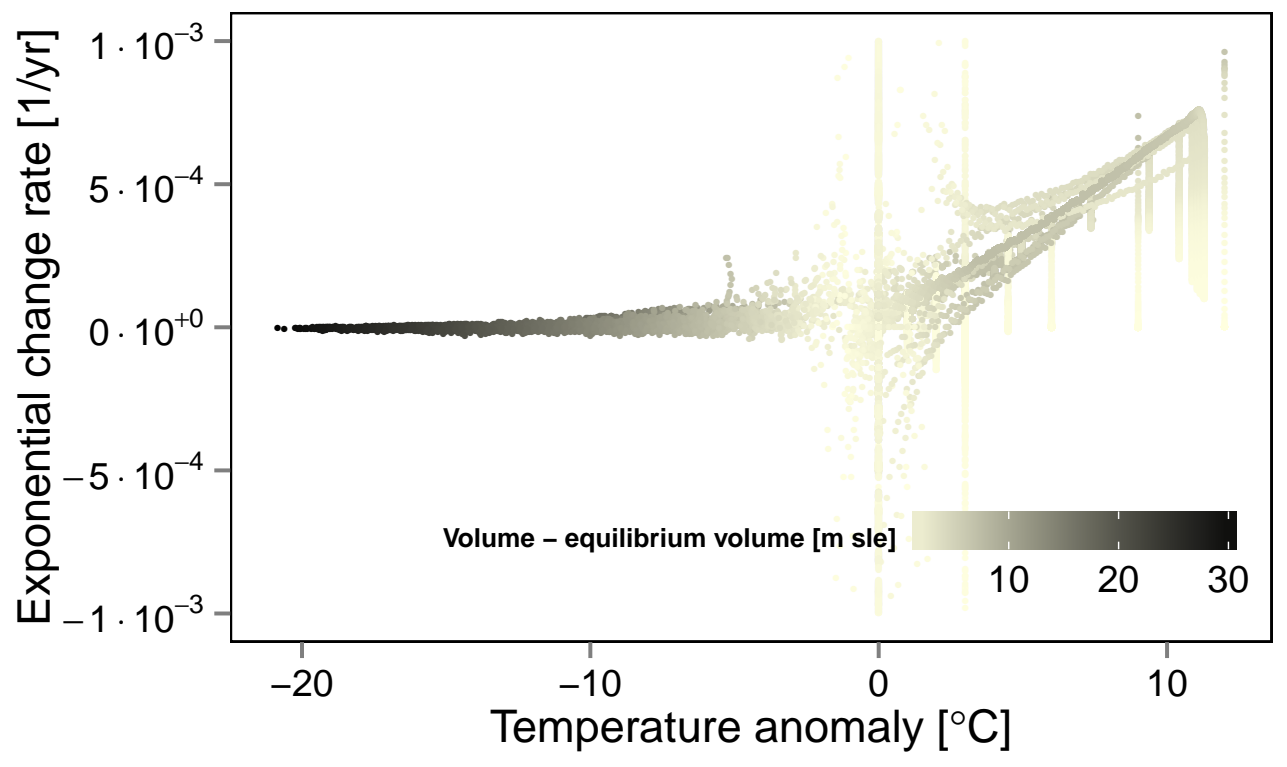

Figure 5: 'Exponential change rate' $1 / \tau$ as a function of temperature $T$. Same simulations are used as for figure 4 . For temperature anomalies between 0 and $12{ }^{\circ} \mathrm{C}$, the exponential decay rate approximately linearly increases with temperature (in case ice volume is not yet equilibrated). 

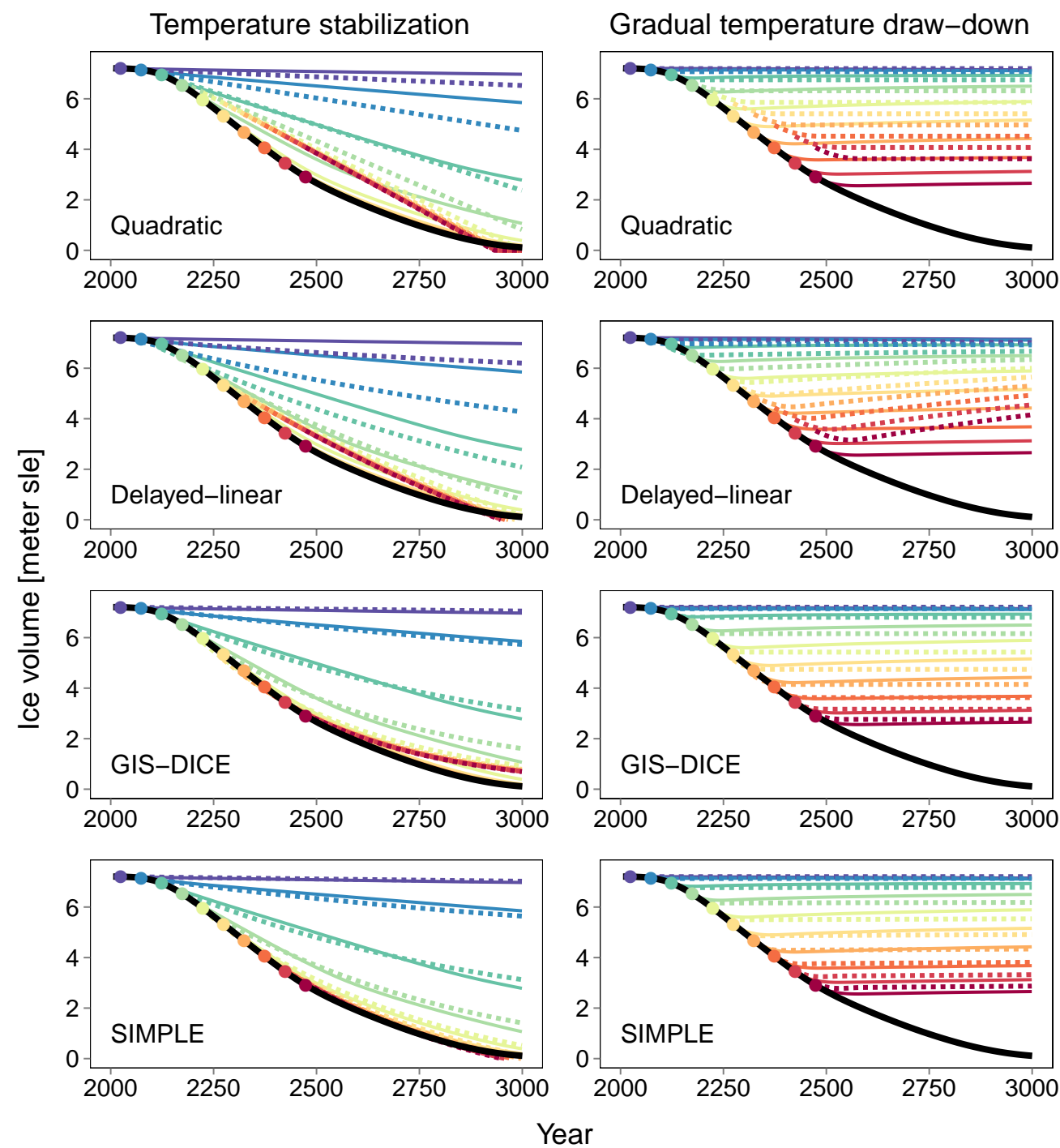

Figure 6: Simulated (SICOPOLIS, solid lines) and emulated (dashed lines) GIS response to 20 different geo-engineering scenarios (left panels: temperature stabilization, right panels: gradual temperature draw-down), where the colors refer to the starting year (dots, see Figure 3). The thick black line is the simulated response to the 'base' RCP8.5 scenario. SIMPLE (bottom row) reproduces SICOPOLIS slightly better than GIS-DICE (third row) and much better than the quadratic function (upper row) and the delayed linear concept (second row). 


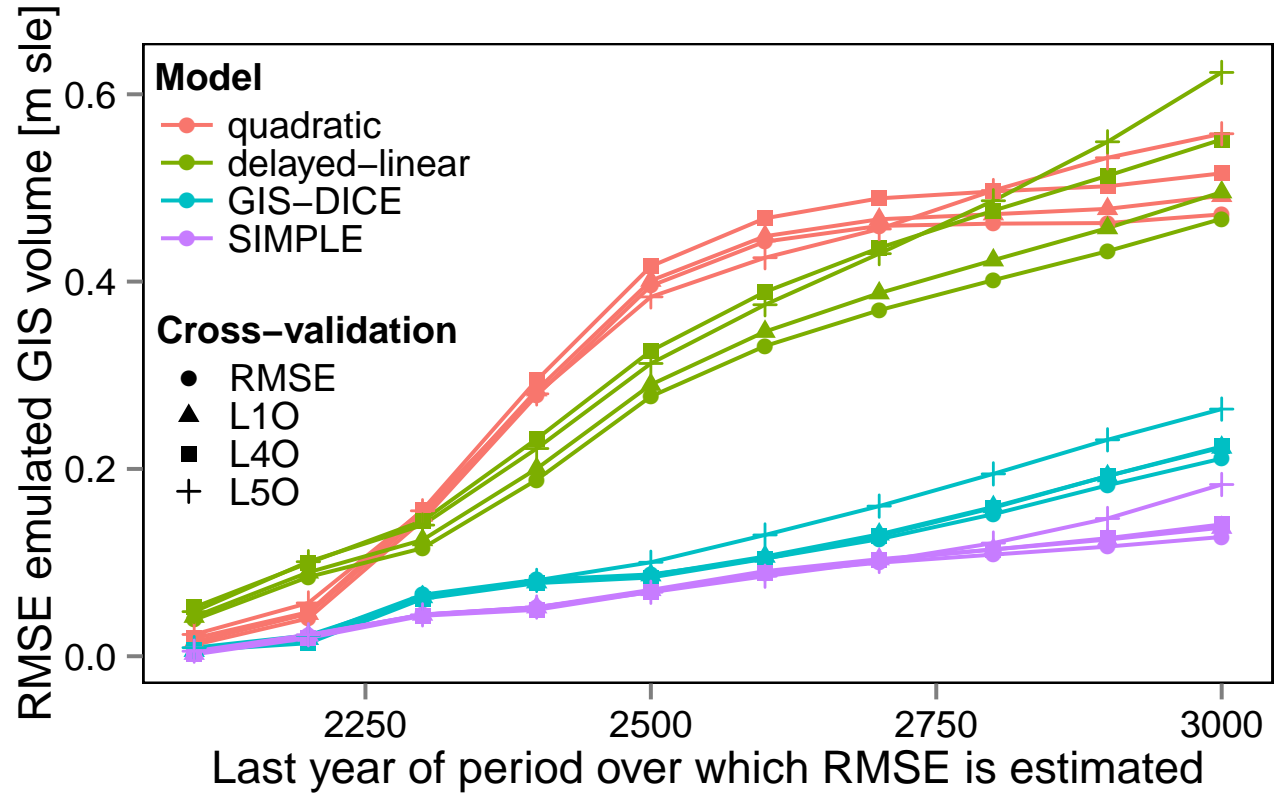

Figure 7: RMSE (Root Mean Squared Error) of emulated GIS volume as a function of evaluation time as emulated by SIMPLE and other emulators (colors) estimated by different cross-validation strategies (symbols). RMSE is evaluated against the SICOPOLIS geo-engineering scenarios (see figure 3) for different time spans into the future (horizontal axis). SIMPLE shows smallest RMSE and lowest sensitivity for calibration data. 


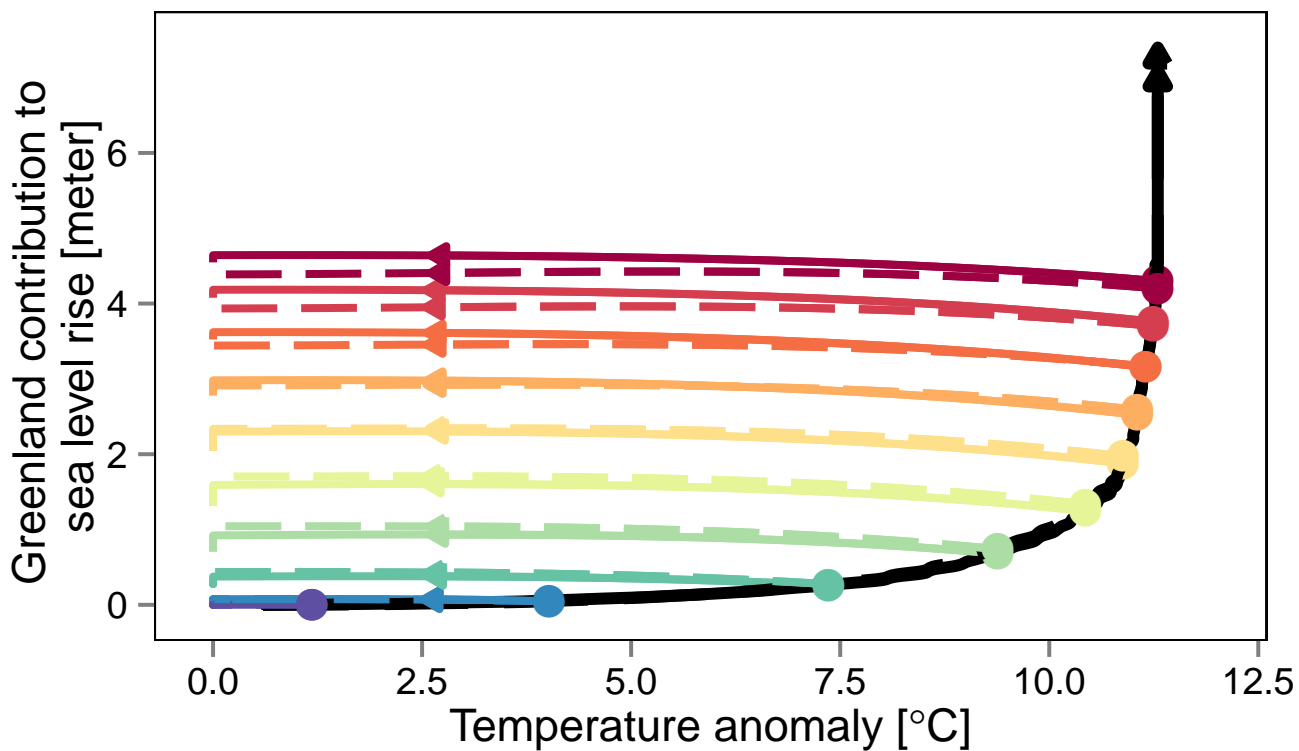

Figure 8: Simulated (SICOPOLIS, solid lines) and emulated (SIMPLE, dashed lines) change path dependent behavior (sea-level contribution as a function of temperature). Transient response to Greenland surface temperature forcings according 10 geo-engineered temperature 'draw-down' scenarios (see figure 3, right panel). Colors refer to starting year (dots) geo-engineering. 


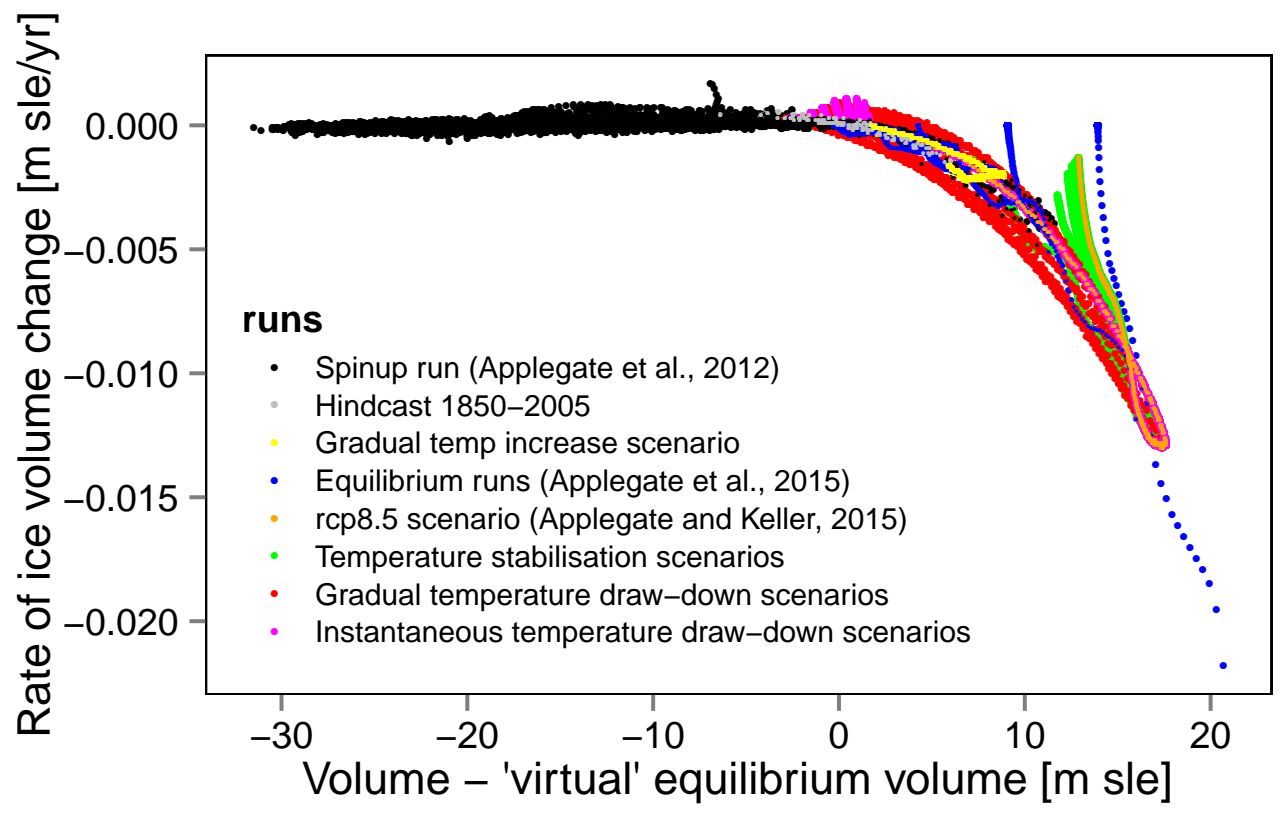

Figure A.9: As figure 4, but colors refer to model simulations rather than to ice volume 